Review Article

\title{
Issues and challenges related to breastfeeding during COVID-19 pandemic
}

\author{
Manish Taywade ${ }^{1 *}$, Swayam Pragyan Parida ${ }^{1}$, Dhariti Swain ${ }^{2}$, Hrushikesh Das ${ }^{2}$
}

${ }^{1}$ Department of Community Medicine and Family Medicine, ${ }^{2}$ College of Nursing, AIIMS Bhubaneswar, Odisha, India

Received: 05 January 2021

Accepted: 18 January 2021

\section{*Correspondence:}

Dr. Manish Taywade,

E-mail: drmanishtaywade@gmail.com

Copyright: (C) the author(s), publisher and licensee Medip Academy. This is an open-access article distributed under the terms of the Creative Commons Attribution Non-Commercial License, which permits unrestricted non-commercial use, distribution, and reproduction in any medium, provided the original work is properly cited.

\begin{abstract}
The COVID-19 pandemic has drastically affected continuum of care throughout the life. To "bend the curve", regarding argument among all the research community whether positive or symptomatically suspected COVID-19 mother isolation can reduce the risk of transmission to new born. The recommendation is, infant and Mother's should be enabled to remain together and practice kangaroo mother care. Breastfeeding is most essential for an infant growth and development and maternal psychology, evidences till now supporting exclusive breastfeeding is been only been beneficiary and it will be an injustice to obstruct in the wake of this pandemic. The spread of active SARS-CoV-2 virus that can cause infection through breast milk and breastfeeding has not been detected so far.
\end{abstract}

Keywords: COVID-19, Breast feeding, Pandemic, Donor human milk, Kangaroo mother care, Human milk bank

\section{INTRODUCTION}

Coronavirus pandemic has posed global and local challenges to all researchers, scientists, and public health experts. In India, as the shutdown has been imposed all routine outpatient and field activities are withholding in such a scenario the most effected is immunization and village health nutrition day.

Breastfeeding practices have a serious concern during the COVID-19. As a normative standard, breastfeeding is only universal safest option of infant nutrition in disaster situations. ${ }^{1}$ World Health Organization recommended mothers suspected or confirmed case of COVID-19 should be encouraged to initiate and continue breastfeeding at the time of birth and thereafter. Practicing the rooming-in, skin to skin contact, kangaroo mother care, the lactating mother also should continue the breastfeeding. ${ }^{2}$ Breastfeeding has multiple benefits for the mothers, infants to prevent many short-term and longterm consequences..$^{3-5}$
Global public health recommendation is start early breastfeeding. To achieve the optimal growth and development the exclusively breast feeding continue till six month and later two years of life. ${ }^{6}$

Evidence is weak suggesting the presence of coronavirus in breast milk and the possibility of mother-infant transmission. ${ }^{7}$ Studies conducted among different sample sizes tested for COVID-19 and the testing results demonstrating no evidence of active SARS-CoV-2 virus in breast milk. ${ }^{8-12}$

Case series suggested that perinatal SARS-CoV-2 transmission to newborns from infected women may occur, is unlikely, and rooming-in and breastfeeding practices should be allowed with appropriate precautions. $^{8,13,14}$ Case reports revealed the presence of COVID-19 RT-PCR in breast milk samples, but no adverse infant outcomes were reported. ${ }^{15-17}$ However, two individual case series have reported higher transmission rates of $7.1 \%$ and $9.1 \%$ through breast milk. ${ }^{18}$ 
COVID-19 infected mothers were proven to be protected against antibody and their babies had presented with less respiratory illness with fever because of transfer of antibodies in breast milk. A recent published study shows out of 15 previously infected mothers 12 mothers have developed a strong IgA antibody SARS-CoV-2 immune response in breast milk. ${ }^{19}$

Active SARS-CoV-2 viral nucleic acid has not been detected in breast milk in a current study. The benefits of breastfeeding may outweigh the risk of SARS-CoV-2 infection in infants. ${ }^{20}$ Hessami et al conducted a systematic review and concluded previous co-morbidities of mothers and prematurity rather than COVID-19 infection are responsible for maternal and neonatal mortality. $^{21}$ World Health Organization (WHO) and Indian Council of Medical Research (ICMR), recommends exclusive and early continues breastfeeding with proper precautions for positive COVID-19 and suspected mothers. ${ }^{22,23}$

\section{BREASTFEEDING ISSUES DUE TO COVID-19 PANDEMIC}

Routine outpatient services are suspended and due to travel restriction, the support for the breastfeeding is warranted. Many times short stay in a hospital could not provide an opportunity to teach breastfeeding issues, like attachment, positioning, expression of breast milk etc.

Guidance regarding the care of neonates whose mothers have confirmed or suspected COVID-19 is conflicting. WHO and the United Kingdom royal college of obstetricians and gynecologists recommended that mothers and neonates room-in and breastfeed, with appropriate precautions, emphasizing that the benefits of breastfeeding outweigh the potential risks of transmission.

A cohort reports for 116 confirmed COVID-19 positive mothers given births to 120 newborn with rooming-in and breastfeeding with proper national guidelines with wearing mask and hand washing has no altered outcome for both mother and infant with the presence of positive mother. ${ }^{24}$ The study supports that isolation is a significant stressor for newborn infants and could worsen the disease course for those infants already infected with SARSCoV-2. ${ }^{25,26}$ However, the American academy of pediatrics and the United States centers for disease control and prevention (CDC) advises separation of mothers and newborns from birth, with expressed breast milk feeding by uninfected caregivers until criteria are met. As no evidence to show that early separation improves outcomes instead there is much evidence to support separating mother and baby immediately after birth may make the infant more vulnerable to severe respiratory infections, including COVID-19, in the first year of life. At the same time, new evidence in the practice of breastfeeding is emerging daily and may bring safe breastfeeding practice issues related to maternal and fetal outcomes.

\section{BREASTFEEDING CHALLENGES DUE TO COVID-19 PANDEMIC}

Numerous challenges are imposed for a newborn by the coronavirus. The most important is the newborn nutrition followed by support, care to the lactating mothers, skin to skin contact and support from family in the newborn care. In the absence of the mother, feeding should be offered by healthy caregiver to the newborn. To tackle this virtual collaborative network of human milk bank (HMB) has been formed. ${ }^{27} \mathrm{~A}$ comprehensive newborn nutrition and care approach can be offer with optimal lactation support, accessibility and supply to pasteurized donor human milk (PDHM) from HMB is needed to improve neonatal health outcomes. ${ }^{28}$

\section{ACCESS TO MOTHERS' MILK}

Because of suspended routine healthcare, travel restriction made the inaccessibility and unavailability to feeding support. Whereas mothers post delivery hospital stay has been reduced, if their newborns are in neonatal intensive care units (NICU) they should be trained with breastfeeding and expressed feeding process. This would help them restore to the same practice at home. Many of the institutional rules limitations and directive mother of COVID-19 confirmed are separated to the discrete COVID wards poses challenges in the initiation and continue the breast feeding. Few facilities can manage to keep mother and baby together to enhance the practice of breastfeeding under the guidance of trained staff with highly strict preventive measures. Few places are following the early discharge policy which calls challenge to adequate and exclusive breast feeding, on the contrary, few healthcare facility not prefer to discharge babies. Providers or family members play a key role to follow appropriate behavior with a strict measure of personal hygiene measure with the use of mask should provide support in breastfeeding and caring for newborns. ${ }^{29}$ Many of the healthcare infrastructure have been seen to provide music therapy, religious reading classes so that feel relaxed to mother which will ultimately improve lactation in breast feeding mothers in a addition during this pandemic dedicated separate rooms where allocated in NICU by obeying COVID-19 universal guideline like initial thermal and symptoms screening with adherence to sanitation in regular intervals, arranging adequate breast pumps for expressing milk. Some hospital are also educating/informing mothers with dedicate helpline, live chats with an aim for guided continuous breastfeeding. ${ }^{28}$

\section{ROOMING-IN AND KANGAROO MOTHER CARE}

Rooming in and possible skin to skin contact should to permitted to round the clock for all symptomatic and positive mothers and infants. ${ }^{30,31}$ Public health professional guidance's suggest every institution should 
have isolation facility for rooming in with direct breastfeeding should take place in case not having should possible separate till tested negative. ${ }^{31}$ Few institutions have promisingly formed COVID-19 dedicated postnatal wards with added tele-counselling from lactation counselors. $^{28}$

\section{DONOR HUMAN MILK}

In NICU pasteurized donor human milk is life-sustaining an alternative to mother's milk. ${ }^{32}$ Heat treatment of donor milk at $60^{\circ} \mathrm{C}$ for 30 minutes has been shown to deactivate Middle East respiratory syndrome (MERS) coronavirus. ${ }^{33}$ Challenges are many in continuing the service on human milk due to imposed containment zone and lockdown staffs in the human milk bank where restricted to function to outsourcing and milk culture along with transportation. Guidelines for isolation should be coupled with interrupted human milk processing and transportation in a earliest to decrease demand. ${ }^{28,34}$ National guidelines for lactational management is to form facility based lactation units and encourage pasteurized donor milk instead of formula feeds in all public health facilities.

\section{AVAILABLE OPTIONS FOR BREASTFEEDING PRACTICE}

All three key weapons, use of facemask, hand hygiene, and respiratory etiquettes are important steps in the prevention and control of infection from mother to newborn. If the separation of mother and newborn is made, the mother is encouraged to express their breast milk so that milk supply will be maintained. Breast pumps should be provided in such cases and practice of hand hygiene should be promoted. The cleaning and disinfection of breast pumps should be done as per the manufactures instruction. In rooming-in mother use the face mask and maintained hand hygiene before and after each feeding.

Primary health care centers will have lactation support units. Lactation management units and comprehensive lactation management centers are at the secondary and tertiary levels of care respectively. ${ }^{25}$ Isolated rooms with visitors, relatives are not allowed. The physical distancing should be maintained 6 feet $/ 2$ meters when not breastfed. During breastfeeding respiratory etiquette must follow, hand hygiene should be maintained before and after breastfeeding and contact with infant/child, frequent disinfection and cleaning the surfaces, the mother should wear a surgical mask. In the case of expressed breast milk feeding hand hygiene vital. In the case of infected COVID-19, mother donated human milk should be considered. In India, most of the time mother and baby discharged within 48 hours. Newborn screening and pharyngeal swab for coronavirus should be arranged. Whenever possible, the preferred option is that of joint management of mother and newborn, to facilitate the interaction and initiation of breastfeeding. ${ }^{24}$
The role of telemedicine or teleconsultation in the promotion of breastfeeding during the COVID-19 pandemic may be the best option during this disaster. Tele-consultation with health care providers, lactation consultants, skilled manpower, and sharing of the specific helpline number to mothers can solve many issues faced by mothers during the lockdown, shut down, containment zones. Breastfeeding support can be established by mothers who have successfully breastfed, self help group (SHG), women groups who can act as change agents for society. It will help the mother to understand the lactation process and the importance of breastfeeding. The positioning and attachment during breastfeeding are important. Telemedicine helps deliver services in urban areas. ${ }^{35}$ Involvement of social medial to counter the emerging misconception and myths about discouraging breastfeeding and disseminating the fact about the benefits of breastfeeding and other healthy infant feeding practices during this pandemic is highly recommended.

\section{CONCLUSION}

Breastfeeding is the only universal method to prevent neonatal, infant morbidity, and mortality. Corona pandemic is no exception for universal breastfeeding. Lactation management systems are needed to strengthen during and beyond the pandemic. Nutrition during a pandemic is of utmost importance and also the responsibility of all stakeholders. The risk of depression and anxiety among the mothers' increases during COVID19. The support from family and health care professionals should be strengthened to protect mental health and to be continued breastfeeding.

\section{Funding: No funding sources Conflict of interest: None declared Ethical approval: Not required}

\section{REFERENCES}

1. Barfield WD, Krug SE. Disaster preparedness in neonatal intensive care units. Pediatrics. 2017;13920170507.

2. Breastfeeding and COVID-19. Available at: https://www.who.int/news-room/commentaries/ detail/ breastfeeding-and-covid-19. Accessed on 20 November 2020.

3. Stuebe AM, Jegier BJ, Schwarz EB, Green BD, Reinhold AG, Colaizy TT, et al. An online calculator to estimate the impact of changes in breastfeeding rates on population health and costs. Breastfeed Med. 2017;12:645-58.

4. Olson CM, Strawderman MS, Hinton PS, Pearson TA. Gestational weight gain and postpartum behaviors associated with weight change from early pregnancy to 1 y postpartum. Int J Obes. 2003;27: 117-27.

5. Stuebe AM, Rich-Edwards JW, Willett WC, Manson JE, Michels KB. Duration of lactation and 
incidence of type 2 diabetes. J Am Med Assoc. 2005;294:2601-10.

6. The world health organization's infant feeding recommendation. Available at: https://www.who.int/ nutrition/topics/infantfeeding_recommendation/en/. Accessed on 20 November 2020.

7. Lackey KA, Pace RM, Williams JE, Bode L, Donovan SM, Järvinen KM, et al. SARS-CoV-2 and human milk: What is the evidence?. Matern Child Nutr. 2020;16(4):e13032.

8. Chen H, Guo J, Wang C, Luo F, Yu X, Zhang W, et al. Clinical characteristics and intrauterine vertical transmission potential of COVID-19 infection in nine pregnant women: a retrospective review of medical records. Lancet. 2020;395:809-15.

9. Liu W, Wang J, Li W, Zhou Z, Liu S, Rong Z. Clinical characteristics of 19 neonates born to mothers with COVID-19. Front Med. 2020;14:1938.

10. Fan C, Lei D, Fang C, Li C, Wang M, Liu Y, et al. Perinatal transmission of 2019 coronavirus diseaseassociated severe acute respiratory syndrome coronavirus 2: should we worry?. Clin Infect Dis. 2020; 17

11. Li Y, Zhao R, Zheng S, Chen X, Wang J, Sheng X, et al. Lack of vertical transmission of severe acute respiratory syndrome coronavirus 2, China. Emerg Infect Dis. 2020;26:1335-6.

12. Schwartz DA. An analysis of 38 pregnant women with COVID-19, their newborn infants, and maternal-fetal transmission of SARS-CoV-2: maternal coronavirus infections and pregnancy outcomes. Arch Pathol Lab Med. 2020;144(7):799805.

13. Zeng L, Xia S, Yuan W, Yan K, Xiao F, Shao J, et al. Neonatal early-onset infection with SARS-CoV-2 in 33 neonates born to mothers with COVID-19 in Wuhan, China. JAMA Pediatr. 2020;174:722.

14. Zhu H, Wang L, Fang C, Peng S, Zhang L, Chang $\mathrm{G}$, et al. Clinical analysis of 10 neonates born to mothers with 2019-nCoV pneumonia. Transl Pediatr. 2020;9:51-60.

15. Buonsenso D, Costa S, Sanguinetti M, Cattani P, Posteraro B, Marchetti S, et al. Neonatal late onset infection with severe acute respiratory syndrome coronavirus 2. Am J Perinatol. 2020;37:869-72.

16. Wu Y, Liu C, Dong L, Zhang C, Chen Y, Liu J, et al. Coronavirus disease 2019 among pregnant Chinese women: case series data on the safety of vaginal birth and breastfeeding. BJOG An Int J Obstet Gynaecol. 2020;127:1109-15.

17. Groß R, Conzelmann C, Müller JA, Stenger S, Steinhart K, Kirchhoff F, et al. Detection of SARS CoV-2 in human breastmilk. Lancet. 2020;395: 1757-8.

18. Wang S, Guo L, Chen L, Liu W, Cao Y, Zhang J, et al. A case report of neonatal 2019 coronavirus disease in China. Clin Infect Dis. 2020;71:853-7.

19. Fox A, Marino J, Amanat F, Krammer F, HahnHolbrook J, Zolla-Pazner S, et al. Evidence of a significant secretory-IgA-dominant SARS-CoV-2 immune response in human milk following recovery from COVID-19. medRxiv. 2020;5:20089995.

20. Liu E, Smyth RL, Luo Z, Qaseem A, Mathew JL, Lu Q, et al. Rapid advice guidelines for management of children with COVID-19. Ann Transl Med. 2020;8:617.

21. Hessami K, Homayoon N, Hashemi A, Vafaei H, Kasraeian M, Asadi N. COVID-19 and maternal, fetal and neonatal mortality: a systematic review. J Matern Neonatal Med. 2020;16(1):6.

22. Breastfeeding advice during the COVID-19 outbreak. Available at: http://www.emro.who.int/ noncommunicable-diseases/campaigns/breastfeeding-advice-during-the-covid-19-outbreak.html. Accessed on 20 November 2020.

23. Guidance for management of pregnant women in COVID-19 Pandemic. Available at: https://covid.aiims.edu/guidance_for_management_ of_pregnant_women_in_covid19_pandemic_120420 20/. Accessed on 20 November 2020.

24. Salvatore CM, Han J-Y, Acker KP, Tiwari P, Jin J, Brandler $M$, et al. Neonatal management and outcomes during the COVID-19 pandemic: an observation cohort study. Lancet Child Adolesc Heal. 2020;4:721-7.

25. Moore ER, Bergman N, Anderson GC, Medley N. Early skin-to-skin contact for mothers and their healthy newborn infants. Cochrane Database Syst Rev. 2016 ;25:22.

26. Morgan BE, Horn AR, Bergman NJ. Should neonates sleep alone?. Biol Psychiatry. 2011;70: 817-25.

27. Lactation management centres in public health facilities National guidelines. Available at: https://nhm.gov.in/images/pdf/programmes/IYCF/N ational_Guidelines_Lactation_Management_Centres .pdf. Accessed on 20 November 2020.

28. Taft J. Helping to ensure safer transitions in hospitals. JAAPA. 2008;21:59-61.

29. Guidance for use of human milk in India in the context of COVID-19 Guidance for use of human milk in India in the context of COVID-19. Available at: https://www.path.org/resources/guidance-usehuman-milk-india-context-covid-19/. Accessed on 20 November 2020.

30. Davanzo R, Moro G, Sandri F, Agosti M, Moretti C, Mosca F. Breastfeeding and coronavirus disease2019: Ad interim indications of the Italian Society of Neonatology endorsed by the Union of European Neonatal \&amp; Perinatal Societies. Matern Child Nutr. 2020;26:3.

31. Clinical management of severe acute respiratory infection (SARI) when COVID-19 disease is suspected: interim Guide. Available at: https://www.who.int/docs/defaultsource/coronaviruse/clinical-management-of-novelcov.pdf. Accessed on 20 November 2020. 
32. Furlow B. US NICUs and donor milk banks brace for COVID-19. Lancet Child Adolesc Heal. 2020; $4: 355$.

33. Van Doremalen N, Bushmaker T, Karesh WB, Munster VJ. Stability of Middle East respiratory syndrome coronavirus in milk. Emerg Infect Dis. 2014;20:1263-4.

34. Shenker N, Aprigio J, Arslanoglu S, Aye NSS, Bærug A, Bar Yam N, et al. Maintaining safety and service provision in human milk banking: a call to action in response to the COVID-19 pandemic. Lancet Child Adolesc Heal. 2020;4:484-5.
35. Kapinos K, Kotzias V, Bogen D, Ray K, Demirci J, Rigas MA, et al. The use of and experiences with telelactation among rural breastfeeding mothers: Secondary analysis of a randomized controlled trial. J Med Internet Res. 2019;21:9.

Cite this article as: Taywade M, Parida SP, Swain D, Das H. Issues and challenges related to breastfeeding during COVID-19 pandemic. Int J Community Med Public Health 2021;8:1528-32. 